\title{
"With Friends Like These": Unpacking Panicked Metaphors for Population Ageing
}

\author{
Sally Chivers (1)
}

check for

updates

Citation: Chivers, S. "With Friends Like These": Unpacking Panicked Metaphors for Population Ageing. Societies 2021, 11, 69. https:// doi.org/10.3390/soc11030069

Academic Editors: Ieva Stončikaite and Lucie Vidovićová

Received: 4 June 2021

Accepted: 25 June 2021

Published: 1 July 2021

Publisher's Note: MDPI stays neutral with regard to jurisdictional claims in published maps and institutional affiliations.

Copyright: (C) 2021 by the author. Licensee MDPI, Basel, Switzerland. This article is an open access article distributed under the terms and conditions of the Creative Commons Attribution (CC BY) license (https:/ / creativecommons.org/licenses/by/ $4.0 /)$.
Departments of English Literature and Gender and Social Justice, Trent Centre for Aging and Society, Trent University, Peterborough, ON K9J 7B8, Canada; sallychivers@trentu.ca

\begin{abstract}
Age studies scholars have long noted problems with using a tsunami metaphor to describe population ageing. Age-friendly offers a new way to respond to an increase in older adults. Though critical gerontologists identify the related movement's limits, "age-friendly" itself is rarely recognized as a metaphor. This paper proposes that, while the metaphor of age-friendly is more benign than that of the tsunami, it still portrays an ageing population as a homogenous problem to be solved through morally obligatory individual actions, thereby participating in a form of age panic. The analysis draws on a humanities-based close reading of the World Health Organization's 2007 "Global Age-Friendly Cities: A Guide." The method uncovers attitudes that anchor the metaphor and hamper the movement's effectiveness, particularly when trying to reach people who have not already been well served all their lives. The emphasis on a narrow version of active ageing feeds a neoliberal imagination that affects how value is assigned to an ageing population. That underlying emphasis needs to shift before new metaphors, policies and practices for population ageing-that allow for the variability and uniqueness of late-life experience-can take hold. How might we reconceptualize the ageing population if we focus on contributions and meaning instead?
\end{abstract}

Keywords: active ageing; age-friendly; age panic; metaphor; neoliberal imagination

\section{Introduction}

The silver tsunami, a persistent metaphor to describe population ageing, encourages people to dread and fear not only an increase in older adults but, above all, an increase in so-called frail older people and, even more so, people with dementia. The metaphor is effective because it has shock value, it relies on the idea that people do not want to grow old if doing so involves physical or mental decline, and it implies that the sheer numbers of older adults will soon enough swamp younger generations, preventing the relatively youthful from their otherwise expected contributions, especially to the economy. This ubiquitous comparison to natural disaster feeds what I call age panic, a concept that draws on an elucidation of moral panic [1-3]. The incited panic makes ongoing good health, narrowly defined, the moral responsibility of the individual ageing person.

Critical age studies scholars identify this highly negative and obviously ageist tsunami metaphor as a tired ploy for attention to a set of pressing issues, usually to economize biological, social, and cultural ageing [4-12]. Contributing to that discussion, Amanda Barusch acknowledges attempts to find a better metaphor (than the tsunami) for the ageing population, explicitly referencing the World Health Organization's (WHO) "benign metaphor of city as friend in its initiative to promote 'age-friendly' communities" [8] (p. 183). Barusch thereby raises the essential point that an entire movement created to resist ageism relies upon a metaphor that is rarely recognized as figurative language.

The tsunami and age-friendly metaphors invoke seemingly disparate images of natural disaster and interpersonal relations to assign responsibility for ageing well to the individual. A metaphor is a figure of speech that yokes together two dissimilar objects-that literary scholars name the tenor and the vehicle-without adding a comparator word such as 
"like" or "as." The comparisons thereby emphasize both the differences and the similarities between the two. I here follow an age studies tradition of metaphorical analysis in pointing out that the connections are not merely linguistic but also have cultural, material, and social consequences because of the concepts they rely upon [7,9,12]. As George Lakoff aptly explains of similar everyday metaphors, "the locus of metaphor is not in language at all, but in the way we conceptualize one mental domain in terms of another" [13] (p. 202). At first glance, the mental domain of the tsunami metaphor is quite different from the mental domain of the friendly metaphor. However, each metaphor draws on its vehicle to compare these domains - of natural disaster and of amicability — with the effects of an ageing population that they reduce to a set of health care and financial problems to be solved. Barusch is right to indicate that we need new metaphors to describe the effects of population ageing. However, to develop better ones, a broader conceptual shift is necessary. New metaphors-and practices-for ageing are more likely to become possible when we stop reducing the ageing population to a set of problems in need of solutions. Rather than joining Susan Sontag in indicting metaphorical thinking, it is imperative to challenge the thinking that motivates dominant metaphors, some of which-such as the tsunami-are more widely acknowledged as figurative than others-such as age-friendly [14] (p. 3).

\section{Materials and Methods}

To increase understanding of the mechanisms that incite age panic and provide a foundation for strategies to combat it, this article adapts humanities methods to explore the possibilities and limitations of the seemingly benign metaphor of friendliness, promulgated by a WHO-inspired movement that responds to the population ageing that drives the tsunami metaphor. The argument is grounded in an analysis of the WHO's "Global Age-Friendly Cities: A Guide," which lays out how their framework for age-friendly communities relies on and promotes active ageing. The text is ripe for analysis because it reflects consultations that provided the foundation of the age-friendly movement. As such, it conveys not only an official organization's position but also the spirit of what people able to attend consultations shared. The Guide continues to be a central reference in the formulation of age-friendly plans for municipalities and communities who seek agefriendly designations, so it remains a powerful document that invites interrogation of its powerful implications. In particular, the reliance within the Guide on active ageing poses a problem because it turns active ageing into a moral imperative to the extent that the age-friendly movement ironically risks increasing age panic rather than assuaging it as intended [15].

To elucidate the implications of the age-friendly metaphor, I draw on a literary technique to offer a close-reading of the 2007 Guide that launched the age-friendly movement. Those original guidelines persist as a source of information and ideas for communities seeking age-friendly status, even though they are continually revised and updated. Close reading derived from literary studies requires careful, sustained attention to form, patterns, language choice, syntax, themes, and figures of speech. It thereby offers a way to understand the Guide fully and access the at times hidden motivations behind the movement the Guide buttressed. That process allows for a way to think about the implications of implementing practices based on a Guide that is unintentionally rife with bias. Additionally, it makes it possible to do so in a way that does not blame or condemn individuals for their role in creating a document under constraints and based on a genuine attempt at consultation. While the original emergence of close reading resisted context, my adapted approach draws on close reading techniques to illuminate and evaluate the broader milieu in which the Guide operates, such as the austerity context within which consultations took place (which I discuss in more detail in Section 4.2). Recognizing the ideological context in which age-friendly has developed heightens the significance of the textual findings and may help improve the movement's reach. Better understanding the less obvious implications of the age-friendly movement offers a basis from which to reorient age-friendly actions towards the urgent need to work with groups of people-such as migrant workers, 
people cycling in and out of poverty, care workers, people with dementia and other forms of mental illness-who have not benefited from a cumulative set of advantages over time. Those communities within communities fall just outside the purview of many age-friendly projects, despite age-friendly councils and committees' best intentions [16].

I first review critical perspectives from age studies scholars on the implications of the tsunami metaphor, situating it within core concepts from the field. I then offer the close reading of the WHO's "Global Age-Friendly Cities: A Guide" to explain the implications of the age-friendly metaphor as both departing from and reinforcing the assumptions behind the more harmful tsunami metaphor. Finally, I conclude by situating these figures of speech in relation to active ageing and age panic to show how those troubling approaches must be fully understood and interrogated throughout what the WHO has declared the United Nations Decade of Healthy Ageing 2021-2030. That reckoning must occur so that we can genuinely develop more equitable policies and practices for ageing in the twenty-first century, based on the contributions and meaning that an ageing population brings.

\section{Metaphorical Thinking about Population Ageing}

\subsection{The Tsunami Metaphor}

It does not require much analysis to conclude that the tsunami metaphor is inaccurate, harmful, and demands reinvention, resistance, or rejection. As Stephen Katz writes, "the aging population ... is projected as a monstrous entity set upon destroying welfare states and generational futures" [17] (p. 18). The tsunami metaphor hosts the threat that global population ageing will result in a deluge of needy older adults whose decrepitude will swamp with obligation and debt the younger generations who wait helplessly on the shore without hope of secure employment, adequate health care insurance, nor the pensions supposedly enjoyed by the "silver foxes" and "tired hags" who are riding the wave. In the ongoing context of austerity, the behaviour of these "greedy geezers" is intensely threatening because of "debt morality," by whose terms to characterize any social group as a drain on resources is to damn them [18].

Perhaps this all sounds logical. An understandable rhetorical move at this point in popular articles that rely on the concept of population ageing is to cite alarming statistics. The repetitive reliance via the tsunami metaphor on such apocalyptic demography [19] ignores the significant ramifications of literal tsunamis and misinterprets changing dependency ratios. As Andrea Charise has most prominently argued, "the fatal immediacy of the [2011 Japan tsunami] should shock us out of this crude, familiar metaphor. For what could be more 'abstract' than comparing the instantaneous destruction of cities, food and water supplies with the progressive aging of society?" [7] (p. 2). Typically, alarmist demographic predictions indicate a stark increase in dependency ratios, simply described as the number of productive adults available to support the number of supposedly dependent adults. However, as Barusch points out, "children are left out of the dependency ratios used to amplify the aging tsunami message" [8] (p. 182). Including children under fifteen switches the demographic prediction to a decrease rather than an increase in the dependency ratio. Toni Calasanti digs more deeply into the ageism behind the interpretation of dependency ratios, arguing that "both the total and economic dependency ratios were higher in the 1970s, yet I am unaware of government or pundits complaining of too many children then, or the need to cut back on spending on youth" [12] (p. 204). Calasanti also emphasizes how dependency ratios define contribution solely in terms of paid labour, ignoring unpaid labour, let alone other forms of human value.

What lies beneath the tsunami rhetoric is, of course, deep ageism, a casual or systematic set of prejudices and discrimination based on age. However, it is also gerontophobia, which implies a fear of older people and a fear of being recruited to become one, together with the moral imperative to refuse to become a certain kind of older person [20] (p. 21). The tsunami metaphor relies on assumptions about contribution, deserving, and consumption, abandoning old age to a limiting narrative of decline [21]. Further, that decline story is relevant not only because of the apparent decay of the body but also because it foregrounds 
how older adults will burden the economy through increasing over-reliance on health care systems, understood in terms of financial cost. Fear arises from the mistaken idea that these older people will further sap the more valuable time of younger generations who should themselves both contribute to the economy and attend to self-care so as not to be swept away by the wave themselves.

Of course, everyone will be old if they live long enough. However, the tsunami discourse is not about chronological age so much as it is about age occupying a social space and acting as a cultural field [22]. Fear arises not from the prospect of living into what some sociologists call the third age, loosely denominating a group of wealthy active agers in relatively good health [23]. Fear arises instead from the prospect of entering the fourth age, which theorists explain is not only a chronological but more so a social and cultural shift from the third age. As Chris Gilleard and Paul Higgs explain it, "It is when people are no longer 'getting by,' when they are seen as not managing the daily round, when they become third persons in others' age-based discourse, within others' rules, that they become subjects of a fourth age" [22] (p. 122). That is, it is when they are swept up by the wave rather than left waiting on the shore.

Liz Lloyd describes the fourth age as "characterised by the combination of advanced chronological age, bodily decline, loss of functional health and mobility and increasing dependency on others for help with everyday activities" [24] (p. 261). Put simply, for wealthy Western people, one is not "old" unless (rather than until) one is in the fourth age. That is also to say one is not old until one experiences decrepitude, which is the disposition that most elicits age panic. Thus, the panic evoked by the tsunami metaphor and related rhetoric is motivated not only by ageism and gerontophobia but also by ableism, a casual or systematic set of prejudices and discrimination based on ability along with typically ignored intersections with race, gender, class, sexuality, and wealth especially when those arise from cumulative advantages and disadvantages over time. The implication is that the individual must take specific actions to prevent the physical changes that connote growing old in the fourth-age sense of the term.

\subsection{The Age-Friendly Metaphor}

The age-friendly metaphor requires more analysis than the tsunami metaphor because its implications are less obvious and have largely escaped attention from age studies scholars beyond Barusch. Unlike the tsunami metaphor, with its hyperbolic flourishes, agefriendly has always already been a dead metaphor, with the forgotten tenor being the urban environment and the vehicle being a pleasant companion. A much-needed soothing balm to the age panic that drives the tsunami usage, the age-friendly movement is nonetheless motivated by the same dread and fear of a needy ageing population, this time addressed more constructively. There's nothing wrong with the age-friendly metaphor itself-Barusch is right to call it benign. However, as Lakoff reminds us, it is not the language itself but the relational conceptualization that is of concern. Unpacking the metaphor's implications might remove some barriers to achieving the putative goals of the age-friendly movement. To unpack those implications, I turn to a foundational document that continues to anchor the movement.

\section{Global Age-Friendly Cities and Communities}

Launched in 2005, the WHO Global Network for Age-Friendly Cities and Communities involves hundreds of cities and communities, reaching about 130 million people. Though definitions are elusive and contextual, a generally agreed-upon definition of an age-friendly community is a "place where older people are actively involved, valued, and supported with infrastructure and services that effectively accommodate their needs" [25] (p. 4). To operationalize "age-friendly," the WHO recruited cities, developed a research protocol, and consulted older adults to create the 2007 WHO "Global Age-friendly Cities: A Guide" and an associated checklist [15]. The research and consultations that led to the Guide were funded and supported by organizations in Canada, the United Kingdom, 
Lebanon, Brazil, Mexico, Australia, and the United States. Based on research conducted in 33 cities in 21 countries on six continents, the 82 page Guide offers recommendations for transforming an urban environment into a place that welcomes older adults.

As the Guide explains, "Informed by the WHO's approach to active ageing, the purpose of this Guide is to engage cities to become more age-friendly so as to tap the potential that older people represent for humanity" [15] (p. 1). The Guide lays out ways for cities to be adapted so that they are "accessible to and inclusive of older people with varying needs and capacities" [15] (p. 1). As such, it draws on feedback from older people (as well as caregivers and service providers) in the range of cities where consultations took place to make recommendations to municipalities for changes that enrich the participation and lives of the older population. It gathers recommendations for its named target audience, which consists of "individuals and groups interested in making their city more age-friendly, including governments, voluntary organizations, the private sector and citizens' groups" [15] (p. 11). After explaining the context of population ageing during rapid urbanization, introducing active ageing as a basis, summarizing the research process, and offering ideas of how to use the checklists, the Guide divides its findings into eight categories, which are illustrated as petals on a flower to indicate a lack of hierarchy. The areas align with conventional ideas of infrastructure along with social attitudes: outdoor spaces and buildings; transportation; housing; social participation; respect and social inclusion; civic participation and employment; communication and information; and community support and health services. [15] (p. 1). The Guide concludes by repeating that the research on which it is based does "not focus specifically on the crosscutting active ageing determinants of gender and culture" [15] (p. 75), offering a hint about whose perspectives came through most clearly during the consultation process, which was understandably limited to those older adults and other stakeholders who have the means and capacity to participate. The final lines of the Guide reveal how it is enmeshed in economic motivations: "Active ageing in supportive, enabling cities will serve as one of the most effective approaches to maintaining quality of life and prosperity in an increasingly older and more urban world" [15] (emphasis added, p. 75). The term "maintaining" reveals how this movement started out by focusing on people with adequate quality of life and prosperity, rather than seeking to help those who could benefit from improvements. The term "prosperity" speaks to the neoliberal and austerity contexts within which the Guide was developed and within which the movement has flourished.

In the Guide, the WHO personifies the age-friendly city as an adaptable space that "encourages active ageing" [15] (p. 1). In animating the inanimate entity of the city, the Guide imagines cities to be imbued with human characteristics. The personified city is not just any person, but specifically an affable civil servant, polite and full of good ideas about inclusivity and diversity with limited budget and means to implement them. As is usually the case with an underfunded, overworked civil service, the age-friendly city faces an added pressure to be welcoming without the necessary support and resources to make that feasible. However, the Guide does not make as evident this lack of support and resources, emphasizing the need for approachability rather than the means to create change. The compliant figure the WHO Guide evokes is friendly but distinctly not a friend; this is more about appearance than it is about relationship; it is the "friendly" of a sports match not intended to be part of regular season play. Age-friendly does not imply the mutuality of friendship: the Guide does not exhort older adults to be friendly to their physical and social environments in return. Municipalities, and their representatives, must take on this friendly approach aimed at older adults. However, as I discuss in Section 4.1, a closer reading of the Guide raises questions about which older adults appear to deserve a friendly approach (with implications that older adults that do not live up to certain expectations do not merit friendly treatment).

Adding an adverb to the adjective "friendly" is part of a broad linguistic trend in English. Typically, doing so indicates an inclination rather than a concrete plan or policy. Since the 1980s, the English language has welcomed eco-friendly, planet-friendly, butterfly- 
friendly, dog-friendly, tourist-friendly, bike-friendly, development-friendly, family-friendly, child-friendly, and queer-friendly. Similarly, gluten-friendly has counterintuitively become a way to refer to foods that are less likely to cause upset to people sensitive to gluten, without fitting the regulated description "gluten-free." The phrasing is counterintuitive because gluten-friendly foods are quite hostile to gluten but hospitable to people who cannot tolerate the protein. This last usage indicates how adding "-friendly" risks becoming a branding exercise that emulates broader social awareness without having to adhere to related regulations. As Tine Buffel and Chris Phillipson have pointed out, the age-friendly designation similarly risks morphing into a normative white, middle-class brand [16] (p. 174). My close reading suggests that is particularly the case due to the Guide and movement's emphasis on activity and narrow view of participation.

The list of entities that make up the desired target audience ("governments, voluntary organizations, the private sector, and citizens' groups" [15] (p. 11)) implies parallelism among these individuals and groups despite the hopefully quite different goals of each. Of course, in an austerity-driven neoliberal era, the distance between the private and public sector continually decreases; the individual person discursively functions as a microcosm of the social, and vice versa [26]. My close reading of the Guide itself, however, reveals a narrower implied audience through its interpellation of an ideal older adult, familiar from advertisements in which thin, active, usually white, seniors, apparently youthful despite their silvered hair, work in "heterohappy" pairs to buy things and take responsibility for their savings, their health, and their children's futures [27]. Despite the range of consultations, the description of older adults throughout the Guide does not match the expressed desire for inclusivity and accessibility. Instead, the Guide comes across as coercing those older adults who might read it into a particular form of ageing. Even more worrying, the Guide appears to influence policymakers and city planners toward a narrow vision of older citizens that does not challenge the damaging thinking behind the ubiquitous tsunami metaphor. This framing of the ideal senior ignores considerable agency as well as diversity among older adults, especially considering the vast geographical reach of the Guide.

Though many older adults have the desire and capacity to resist this construction, the WHO Guide implies a normative, relatively wealthy, presumably house-owning, hetero, married-once-until-death [15] (p. 41) older adult who welcomes surveillance cameras with nothing to fear from them [15] (p. 15), who needs to learn to ride the bus having apparently always previously owned and driven a car [15] (p. 23, p. 25), who has enjoyed a traditional career arc including a welcomed and easily prepared for retirement [15] (p. 40) during which they volunteer to give back to their communities, and who is now being served rather than serving in the customer service industry. An engaged, lively, fit citizen, they might need to go to a few more medical appointments than before and have a bit more trouble navigating their way to them. Hence, apparently, their need for age-friendly design.

The interpellation of this ideal senior helps to show how and why the movement continually struggles to embrace diversity in a meaningful way and has not yet managed to reach those most likely to live outside of age-friendly spaces who are more vulnerable to the inequitable distribution of resources [16]. From reading the Guide alone, one could easily conclude that age-friendly does not focus so much on communities, as implied by the title, as on a collection of dangerously inspiring third-age individuals, such as one might expect to see pictured on the cover of a retirement magazine or in an advertisement for financial planning. That is especially dangerous if it leads to individual older adults responding to age-friendly initiatives by trying to match this inspirational model rather than by bringing their ongoing needs and ideas to the table. However, it is also worrying when it influences municipal policy and practices.

While the WHO Guide includes the occasional reference to poverty and lowerincome [15] (pp. 29-31, 49, 50, 53, 56, 61, 64, 69, 70), it largely assumes a relatively wealthy older population based on Western norms of work life that imply a period of training in young adulthood, followed by gainful employment, and retirement in early old age. The 
brevity of asides stating that not everyone can expect to retire comfortably betrays the underlying normative expectations, such as "in some areas, economic circumstances force older people to take paid work long after they should have retired" [15] (p. 51). Overall, the Guide implies that people past a certain age would only continue paid employment out of need, rather than out of choice or even desire to continue contributing in that way. What is more, situating these mentions as asides implies that needing to work past the expected retirement age is exceptional. The Guide promotes the assumption that, rather than work, older adults would choose to take on volunteer roles, described as opportunities, to gain a "sense of self worth, of feeling active, and of maintaining their health and social connections" [15] (p. 51). The Guide recommends measuring and assessing these elements in keeping with new public management practices, which treat public institutions as businesses. The Guide goes so far as to suggest that older adults should volunteer to make up for shortfalls in the health care system, rather than highlighting how structural problems lead to volunteers doing healthcare work that should be well paid.

\section{Discussion}

\subsection{The Trouble with Active Aging}

The WHO Guide does not emphasize the structural constraints that arise from the austerity context, such as the shortcomings that make health care systems rely on volunteers to function. As a result, the version of active ageing it musters is particularly troubling, with roots in normative, harmful, neoliberal ideas of health that make the individual responsible $[2,28]$. The age-friendly movement thereby risks participating in the same conceptual framework of contributing, deserving and consuming that motivates the tsunami discourse. The Guide promotes the creation of inclusive and accessible urban environments that promote active ageing, revealing its central assumption that active ageing is both possible and desirable for all.

Active ageing may come across as a seemingly harmless descriptor of healthy actions required to procure a desirable or even bearable late life, to appear youthful so as not to scare the actually youthful, and to save the economy from the burden of healthcare needs. However, active ageing in this context refers not to the potential individual benefits of physical activity but to a policy discourse that has seeped into popular usage. It joins related terms, such as successful ageing and healthy ageing, under a broader but vague banner of "aging well" [29] (p. 84). While active ageing-more prominent in Europemoves beyond successful ageing - more prominent in the U. S. - which focuses on ability and functional capacity, active ageing mirrors much of that concept's normative force, particularly in how the WHO Guide deploys it [30]. As framed within the Guide, active ageing becomes both the anchor for creating age-friendly communities and a broader way of conveying to an ageing population who and what they should be, through what they ought to be able and want to do. As critical gerontologists and age studies scholars have firmly and repeatedly established, active ageing runs the risk of wedding late-life success to the neoliberal imagination when it becomes the individual's responsibility [29,31]. Being active in late life is not necessarily a bad thing. Still, there is a dangerous imperative in a euphemistically conceived, marketable "active ageing" that makes individuals responsible for adopting consumerist practices that have little do with actual health and more to do with alleviating the state from social and financial obligation for an ageing population. Calling an approach that pressures individuals into that responsibility "friendly" covers up the more worrying implications of the movement's reliance on activity, narrowly understood.

Further, within policy discourse, active ageing tends to appear as opposite to or even an antidote for care, especially long-term care [32], which is, of course, thought to be the burden that a younger population would have to bear. As Frode Jacobsen explains, active ageing's normative force extends beyond the imperative to be busy, productive, and healthy to being busy and productive in a particular way. As he puts it,

The ideal older people are portrayed as active in sports or going to the gym and participants in voluntary organizations, rather than spending time watching soap 
operas, enjoying horse races or other activities perhaps more associated with a working-class than an educated middle-class lifestyle. [32] (p. 6)

The risk goes beyond but includes creating a "deserving elder" whose flipside is, of course, another older adult who does not deserve, that is, has not earned through action, social supports that they may need even more later in life. If that older adult needs long-term care, the implication is that their inactivity led to this need. It thereby comes across as a form of preventable greediness rather than as the deserving earned by someone who took all the individual approved steps but somehow still ended up requiring longterm care. The discourse promotes the dangerous idea that remaining within the third age, forever delaying the fourth age, is within individual control and even becomes a moral responsibility.

Invoking a third-age figure and side-lining the so-called fourth age, the Guide leans on friendliness to benignly welcome those who have long been welcome in urban spaces. It does so without meaningfully opening the door for those who, as Buffel and Phillipson put it, experience "the unequal impact of life events and accumulation of ... disadvantages over the life course" [16] (p. 180). Again, this is appearance rather than relationship; this is a customer service rather than a public service approach. This form of active ageing can participate in ageism, not to mention being deeply gendered, racialized and class-based. Additionally, while it is not gerontophobic, ableism drives the form of ageism promoted by this form of active ageing. It, too, is dangerous since, as Joy explains, the age-friendly movement offers a way to produce ideal citizens because "the active senior becomes a symbol to live up to that helps to justify austerity cuts" [33] (p. 2). Following the Guide's logic, the imagined subject has a good quality of life and considerable prosperity that they can only lose due to decline. Individuals must remain active, productive citizens, if no longer gainfully employed, offering their time and efforts through volunteer opportunities to maintain a failing social system.

Similar to that behind age panic, the fear the WHO Guide promotes is of decline tied to debt morality. The Guide declares that "functional capacity ... eventually declines," with the only hope being that people might intervene in the "speed of decline" [15] (p. 6), or at least hide it. Tied to a normative, cohort and class-specific, culturally determined life trajectory, the Guide exhorts the ideal older adult to "confident mobility, healthy behaviour, social participation and self-determination or, conversely, to fearful isolation, inactivity and social exclusion" [15] (p. 72). This coercive language openly requires not just mobility but also confidence. As the Guide conceives it, behaviours and attitudes rather than structures determine "health," and they are the behaviours and attitudesconfident, healthy, social, self-that underwrite a societal structure based on a competitive marketplace rather than on other values that might prevail. The term "self-determination" directly implies responsibility down to the level of individuals governing themselves, a process Wendy Brown calls responsibilization [34]. This characterization leaves little room for the older person who might have legitimate reasons for not wanting to be part of the prescribed collective or desiring collaborative support. As Jacobsen asks, "is there no room for voluntary disengagement?" [32] (p. 8), not to mention, of course, involuntary disengagement. Indeed, the Guide describes such desires as deviant. For example, the Guide reveals that "there is some concern about encroachment into public seating areas by people or groups who are intimidating or who display anti-social behaviour" [15] (p. 13). Is the environment not meant to be "friendly" to those "intimidating" "anti-social" people too?

\subsection{Age Panic and the Neoliberal Imagination}

Like the tsunami metaphor, the age-friendly metaphor ties human value to economic contributions. Attitudes about and experiences of ageing, especially of growing older, suffer when a reductive form of politics that treats everything as a marketplace harnesses the popular imagination. Because we are less likely to achieve (and even desire) what neoliberal thinking values-productivity, efficiency, performance-as we age, this impoverishment 
of the imagination significantly affects older adults. To counter the harm done through these metaphors, we must recognize how they ignite the "neoliberal imagination," a term I take from Ronen Shamir, who describes how the "neoliberal imagination" "collapses the epistemological distinction between economy and society" [26] (p. 6). Under the neoliberal imagination, the social sphere becomes a "specific instance of the economic domain" [26] (p. 6). This process stealthily infiltrates even those elements of contemporary society many might expect to be least vulnerable to ideas of use-value and commodity, such as higher education and health care, even when they remain primarily publicly funded [35].

Neoliberalism focuses on the market, especially on enabling competition, and neoliberal austerity focuses on saving money to increase participation in that market. Under neoliberal austerity, debt-especially costing the state money—has become a primary economic taboo. Following what Mark Blyth labels a dangerous (and false) idea-that widespread cutbacks will yield economic growth — we are led to believe that if we individually cut back, we will somehow both prosper and contribute to social prosperity [36]. Even if we emerge from this era of austerity, its deeply moral ways of thinking will linger as part of what Shamir calls "a constantly evolving and adapting neoliberal imagination" [26] (p. 3). So, cutbacks and other austerity measures matter, but their deeply internalized effects will take longer to eradicate even if the overt cuts eventually end.

The problems with the age-friendly metaphor match well with the shortcomings of the age-friendly framework itself. The neoliberal imagination incongruously hampers the WHO age-friendly framework and the movement that follows from it. As Joy pinpoints, "AFCs are a policy experiment that can be used to enhance democracy and equity or to extend austerity more deeply into urban governance" [33] (p. 1). They hold great promise not yet fulfilled and perhaps already subverted. Without a clear handle on ageist discourse and the associated beliefs and actions, they risk becoming what Joy wryly calls austerity-friendly communities. Additionally, they hold the worrying potential to become so by responsibilizing the very people they are designed to serve, which is, frankly, not particularly friendly.

\section{Conclusions}

The age-friendly movement offers a constructive response to population aging. My linguistic and conceptual analysis is not meant to diminish or slow down the considerable improvements cities and communities have made worldwide as they prepare to better welcome older adults, contributing to their quality of life and prosperity, as the Guide puts it. However, the positive elements of the movement do not preclude digging deeper so as to better reframe population aging and create changes that consider "the cross-cutting active ageing determinants of gender and culture" and mitigate against age panic [15] (p. 75). Ideally, the frame of active ageing will give way to a more equitable way to think about later life, something that is not obviously promised by the shift to a Decade of Healthy Ageing.

That said, this analysis is not just about language use, and the problem with the agefriendly metaphor is more significant than the resonant language in which it participates. Removing that register does not mitigate the panic that ensues from imagining population ageing as an inevitable financial disaster on the brink of engulfing the younger people in the world. We do need new metaphors for the ageing population, and age studies scholars have already started to find them in literary and cultural production that increasingly considers ageing a central topic worthy of aesthetic and philosophical attention. However, beyond those new metaphors, we need to shift the underlying approaches to the ageing population.

The language matters, but so too does the thinking behind it. Of course, older people can be profitable and productive, including in decidedly neoliberal ways. However, if we consider the broader meaning of human life, using the ageing population as a long-awaited opportunity to do so, many people stand to benefit not only from new metaphors but also from new policies and practices of ageing that consider the variability and uniqueness of late-life experience. 
Ageing is not solely a problem in need of a solution. When we reconfigure human value beyond profit and productivity, what new ways of thinking about an abundance of older adults might prevail? How might we figuratively capture the surfeit of experience, knowledge, and acceptance that often accompanies later life? When we recognize our collective responsibilities, how might we conceive of population ageing? If we push back against narrowly defined active ageing to embrace a more imaginative range of participation and contribution, what metaphors might we live by?

Funding: This research was funded by the Social Science and Humanities Research Council of Canada, grants numbered IG 435-2015-1787 to S. C. and PG 895-2018-1013 to T. D.

Institutional Review Board Statement: Not applicable.

Acknowledgments: My thanks to Tamara Daly and Susan Braedley, along with the Imagine Aging research team, for conversations that shaped my thinking and for responses to the paper-in-progress. I am also grateful to organizers for giving me the opportunity share my work at Uneven Distribution of Humanity: Research Institute on Interdisciplinary Medical Humanities at National Cheng Kung University, Tainan, Taiwan; The Obama Institute for Transnational American Studies at the University of Mainz, Germany; and A Celebration of Ageing: Active Ageing and Vibrant Communities at the University of Windsor, Ontario, Canada. I thank audience members at those events for their generous and generative feedback.

Conflicts of Interest: The author declares no conflict of interest. The funders had no role in the design of the study; in the collection, analyses, or interpretation of data; in the writing of the manuscript, or in the decision to publish the results.

\section{References}

1. Hall, S.; Clarke, J.; Critcher, C.; Jefferson, T.; Roberts, B. Policing the Crisis: Mugging, Law and Order and the State; Macmillan: London, UK, 1978.

2. Pike, E.C. The Active Aging Agenda, Old Folk Devils and a New Moral Panic. Sociol. Sport J. 2011, 28, 209-225. [CrossRef]

3. Kaplan, E.A.; Chivers, S. Alzheimer's, Age Panic, Neuroscience: Media Discourses of Dementia and Care. In Oxford Research Encyclopedia of Communication; Oxford University Press: Oxford, UK, 2018. [CrossRef]

4. Chivers, S. The Silvering Screen: Old Age and Disability in Cinema; University of Toronto Press: Toronto, ON, Canada, 2011. [CrossRef]

5. Chivers, S. Seeing the apricot: A disability perspective on Alzheimer's in Lee Chang-dong's Poetry. In Different Bodies: Essays on Disability in Film and Television; Mogk, M.E., Ed.; McFarland: Jefferson, NC, USA, 2013; pp. 65-74.

6. Chivers, S. "Your own guilty story": Rethinking care relations through David Chariandy's Soucouyant. Can. Lit. 2019, 239, 108-124. [CrossRef]

7. Charise, A. "Let the reader think of the burden": Old age and the crisis of capacity. Occas. Interdiscip. Stud. Humanit. 2012, 4, 1-16. Available online: https://www.utsc.utoronto.ca/people/acharise/wp-content/uploads/sites/17/2014/11/OCCASION_v04_ Charise_053112_0.pdf (accessed on 3 June 2021).

8. Barusch, A.S. The Aging Tsunami: Time for a New Metaphor? J. Gerontol. Soc. Work. 2013, 56, 181-184. [CrossRef]

9. Zeilig, H. Dementia as a Cultural Metaphor. Gerontology 2013, 54, 258-267. [CrossRef]

10. DeFalco, A. In Praise of Idleness: Aging and the Morality of Inactivity. Cult. Crit. 2016, 92, 84-114. [CrossRef]

11. Kriebernegg, U. 'Time to go. Fast not slow': Geronticide and the burden narrative of old age in Margaret Atwood's 'Torching the Dusties'. Eur. J. Engl. Stud. 2018, 22, 46-58. [CrossRef]

12. Calasanti, T. Brown Slime, the Silver Tsunami, and Apocalyptic Demography: The Importance of Ageism and Age Relations. Soc. Curr. 2020, 7, 195-211. [CrossRef]

13. Lakoff, G. The contemporary theory of metaphor. In Metaphor and Thought, 2nd ed.; Ortony, A., Ed.; Cambridge University Press: Cambridge, UK, 1993; pp. 202-251.

14. Sontag, S. Illness as Metaphor and AIDS and Its Metaphors; Doubleday: New York, NY, USA, 1990.

15. World Health Organization. Global Age-Friendly Cities: A Guide. 2007. Available online: https://www.who.int/ageing/ publications/Global_age_friendly_cities_Guide_English.pdf (accessed on 3 June 2021).

16. Buffel, T.; Phillipson, C. A Manifesto for the Age-Friendly Movement: Developing a New Urban Agenda. J. Aging Soc. Policy 2018, 30, 173-192. [CrossRef]

17. Katz, S. What is age studies? Age Cult. Humanit. An. Interdiscip. J. 2014, 1, 17-23. Available online: https:/ /ageculturehumanities. org/WP/what-is-age-studies/ (accessed on 3 June 2021).

18. Forkert, K. The new moralism: Austerity, silencing and debt morality. Soundings 2014, 56, 41-53. [CrossRef]

19. Gee, E.; Gutman, G. The Overselling of Population Ageing: Apocalyptic Demography, Intergenerational Challenges, and Social Policy; Oxford University Press: Oxford, UK, 2000. 
20. Richardson, N. Ageing Femininity on Screen: The Older Woman in Contemporary Cinema; I.B. Tauris: London, UK, 2019.

21. Gullette, M.M. Declining to Decline: Cultural Combat and the Politics of the Midlife; University of Virginia Press: Charlottesville, VA, USA, 1997.

22. Gilleard, C.; Higgs, P. Aging without agency: Theorizing the fourth age. Aging Ment. Health 2010, 14, 121-128. [CrossRef]

23. Marshall, B.L.; Rahman, M. Celebrity, ageing and the construction of 'third age' identities. Int. J. Cult. Stud. 2014, 18, 577-593. [CrossRef]

24. Lloyd, L. The Fourth Age. In Handbook of Cultural Gerontology; Twigg, J., Martin, W., Eds.; Routledge: Abingdon, UK, 2015; pp. 261-268.

25. Alley, D.; Liebig, P.; Pynoos, J.; Banerjee, T.; Choi, I.H. Creating Elder-Friendly Communities. J. Gerontol. Soc. Work. 2007, 49, 1-18. [CrossRef]

26. Shamir, R. The age of responsibilization: On market-embedded morality. Econ. Soc. 2008, 37, 1-19. [CrossRef]

27. Marshall, B. Happily ever after? 'Successful ageing' and the heterosexual imaginary. Eur. J. Cult. Stud. 2017, 21, 363-381. [CrossRef]

28. Katz, S. Active and Successful Aging. Lifestyle as a Gerontological Idea. Rech. Sociol. Anthr. 2013, 44, 33-49. [CrossRef]

29. Foster, L.; Walker, A. Active and Successful Aging: A European Policy Perspective. Gerontologist 2015, 55, 83-90. [CrossRef]

30. Rowe, J.W.; Kahn, R.L. Successful Aging. Gerontology 1997, 37, 433-440. [CrossRef]

31. Van Dyk, S. The appraisal of difference: Critical gerontology and the active-ageing-paradigm. J. Aging Stud. 2014, 31, 93-103. [CrossRef] [PubMed]

32. Jacobsen, F. Active ageing. Int. Pr. Dev. J. 2017, 7, 1-13. [CrossRef]

33. Joy, M. Age Friendly Communities or Austerity Friendly Communities? Austerity and Its Alternatives. 2016. Available online: https:/ / altausterity.mcmaster.ca/documents/w15-oct-10-2017-meghan-joy-afcs-and-austerity.pdf (accessed on 3 June 2021).

34. Brown, W. Sacrificial Citizenship: Neoliberalism, Human Capital, and Austerity Politics. Constellations 2016, 23, 3-14. [CrossRef]

35. Armstrong, P.; Armstrong, H. The Privatization of Care: The Case of Nursing Homes; Routledge: Abington, UK, 2019. [CrossRef]

36. Blyth, M. Austerity: The History of a Dangerous Idea; Oxford University Press: Oxford, UK, 2013. 